\title{
REVIEW
}

\section{Pulmonary hypertension in collagen vascular disease}

\author{
M.M. Hoeper
}

\begin{abstract}
Pulmonary hypertension in collagen vascular disease. M.M. Hoeper. (C) ERS Journals Ltd 2002.

ABSTRACT: Pulmonary hypertension is a serious but often overlooked complication in collagen vascular disease. The understanding of the development of pulmonary hypertension has increased substantially during the last years.

Abnormal proliferation of pulmonary vascular cells is now being regarded as a predominant process leading to pulmonary vascular obliteration. Medical therapy focuses on prostacyclin treatment, which has been shown to improve exercise capacity and haemodynamic variables in patients with several collagen vascular diseases and pulmonary arterial hypertension.

Continuous intravenous prostacyclin remains the standard treatment of associated pulmonary hypertension but less invasive alternatives such as subcutaneous treprostinil, oral beraprost or aerosolized iloprost, as well as, novel substances such as endothelin receptor antagonists may be appropriate for selected patients.

Eur Respir J 2002; 19: 571-576.
\end{abstract}

Hannover Medical School, Dept of Pulmonary Medicine, Hannover, Germany.

Correspondence: M.M. Hoeper, Hannover Medical School, Dept of Pulmonary Medicine, Carl-Neuberg-Str. 1, 30625 Hannover, Germany.

Fax: 495115328536

E-mail: hoeper.marius@

mh-hannover.de

Keywords: Calcinosis, Raynauds phenomenon, oesophageal involvement, sclerodactyly, and teangiectasia (CREST) syndrome, prostacyclin, pulmonary hypertension, scleroderma, secondary, systemic sclerosis

Received: September 162001

Accepted after revision September 17 2001
Pulmonary complications are common in patients with collagen vascular disease. They may occur as a result of the underlying disease or as a complication of its treatment. Interstitial lung disease is the most common pulmonary complication of collagen vascular disease. Pulmonary vascular involvement may occur as alveolar haemorrhage or as pulmonary hypertension. Pulmonary arterial hypertension (PAH) may accompany interstitial lung disease or may be the sole pulmonary manifestation. In any case, the development of pulmonary hypertension is an ominous prognostic sign. This review will focus on the current concepts with respect to pathogenesis and treatment of PAH in collagen vascular disease.

\section{Epidemiological aspects}

Clinically, histologically and from a therapeutic perspective, PAH in collagen vascular disease is often indistinguishable from primary pulmonary hypertension (PPH). The latter disease is characterized by a progressive obliteration of the pulmonary vascular bed. The diagnosis of PPH requires exclusion of well-defined causes of pulmonary hypertension such as interstitial or obstructive lung disease, myocardial or valvular left heart disease or chronic venous thromboembolism. Several diseases may be accompanied by pulmonary hypertension that resembles PPH. Among these diseases are cirrhosis with portal hypertension, human immunodeficiency virus infection, and collagen vascular disease. According to a novel classification, pulmonary hypertension occurring in any of these clinical conditions is referred to as associated PAH, provided that the causes of secondary pulmonary hypertension, mentioned earlier, have been excluded (table 1) [1]. Pulmonary veno-occlusive disease and pulmonary capillary haemangiomatosis have also been reported in collagen vascular disease, but these are extremely rare complications beyond the focus of this review [2-4].

The occurrence of PAH has been reported in association with every known type of collagen vascular disease. However, the frequency of pulmonary hypertension varies substantially. Pulmonary hypertension is a rare complication of rheumatoid arthritis, dermatomyositis and polymyositis. Rapidly progressive pulmonary hypertension may accompany Sjogren's syndrome but this is also a very rare complication. In patients with systemic lupus erythematosus, pulmonary hypertension is found in $5-10 \%$ of all patients [5-7]. In progressive systemic sclerosis, pulmonary hypertension may occur in $10-33 \%$ of the patients $[8,9]$ and this number may be even higher in patients with mixed connective tissue disease [10]. In the Calcinosis, Raynauds phenomenon, oesophageal involvement, sclerodactyly, and teangiectasia (CREST) syndrome (sometimes referred to as the limited cutaneous variant of systemic sclerosis), which was once believed to be a benign variant of systemic 
Table 1.-Classification of pulmonary hypertension

Pulmonary arterial hypertension

Primary pulmonary hypertension

Sporadic

Familial

Associated pulmonary hypertension

Collagen vascular disease

Congenital heart defects

Portal hypertension

HIV infection

Drugs and toxins

Persistent pulmonary hypertension of the newborn

Other forms

Pulmonary venous hypertension

Myocardial disease of the left ventricle or atrium

Valvular heart disease

Extrinsic compression of pulmonary veins

Pulmonary veno-occlusive disease

Other forms

Pulmonary hypertension with respiratory disease or

hypoxaemia

COPD

Interstitial lung disease

Sleep-related breathing problems

Hypoventilation

High altitude

Congenital lung disease

Other forms

Pulmonary hypertension due to chronic thrombotic or

thromboembolic disease

Chronic thromboembolism

Embolic (thrombi, tumour, parasites)

In situ thrombosis

Sickle-cell disease

Pulmonary hypertension due to disease involving the

pulmonary vessels

Inflammatory

Schistosomiasis

Sarcoid

Other forms

Pulmonary capillary haemangiomatosis

Data as modified from the World Health Organization Symposium 1998, Evian, France. HIV: human immunodeficiency virus; COPD: chronic obstructive pulmonary disease.

sclerosis, the incidence of pulmonary hypertension ranges between $10-30 \%$; an autopsy study revealed changes compatible with pulmonary hypertension in $50 \%$ of patients with the CREST syndrome [11]. While pulmonary hypertension in patients with scleroderma is almost exclusively associated with interstitial lung disease, it may be the sole pulmonary manifestation in patients with the CREST syndrome [12].

\section{Pathology and pathogenesis}

The pathogenesis of pulmonary hypertension still needs to be elucidated. Thorough histological examinations have shown that the features of pulmonary hypertension in collagen vascular disease are similar to the findings in PPH. Thus, the major histological findings are media hypertrophy and intimal thickening of the small and medium-sized pulmonary arteries
[13-15]. Plexiform lesions may also be found in associated pulmonary hypertension. In patients with CREST/scleroderma, concentric intimal thickening is a predominant finding [16]. Intimal thickening was long regarded as a fibrosing process but recent studies by TUDER et al. [13] and Cool et al. [17] have shown that endothelial proliferation is a hallmark of pulmonary hypertension in both, sporadic forms and those associated with collagen vascular disease. The plexiform lesions, which resemble glomeruloidlike structures also consist primarily of proliferating endothelial cells that form channel-like structures indicating an angiogenetic process. However, vascular remodelling in $\mathrm{PAH}$ is not exclusively refined to the endothelium, since proliferation of smooth muscle cells has been reported also [18]. These findings in the aggregate have strengthened the hypothesis that PAH is primarily a proliferative disease.

This notion is further supported by the identification of a gene for familial PPH. This bone morphogenetic receptor protein type-2 gene called (BMPR-2) is a member of the transforming growth factor (TGF)-receptor family [19, 20]. BMPR-2 mutations are found not only in familial pulmonary hypertension but also in sporadic PPH [21]. Although the function of BMPR-2 in the lung is not clear, it is probably intimately involved in proliferation and apoptosis of pulmonary vascular cells [22]. MorReLL et al. [23] have recently shown that pulmonary arterial smooth muscle cells exhibit abnormal in vivo growth responses to bone morphogenetic proteins and TGF- $\beta$. There are no studies so far that have investigated the presence of BMPR-2 mutations in patients with associated pulmonary hypertension.

Several other factors contribute to the pathogenesis and progression of pulmonary hypertension. In patients with collagen vascular disease, inflammation is probably an important contributor to the development of pulmonary hypertension. Clustering of macrophages and T-lymphocytes around vascular lesions has been reported in PPH and associated pulmonary hypertension and has been linked to vascular remodelling [16]. Inflammatory cells producing growth factors such as platelet-derived growth factor or vascular endothelial cell growth factor have been also linked to the pathogenesis of pulmonary hypertension [24-26]. The traditional concept that pulmonary hypertension may be a result of prolonged or extensive pulmonary vasoconstriction has been challenged by the findings described earlier. However, some degree of vasoconstriction may be present in PAH associated with collagen vascular disease, and may be a target of treatment.

Pulmonary in situ thrombosis is a contributing factor in PPH that may also be involved in pulmonary hypertension associated with collagen vascular disease $[27,28]$. Furthermore, thrombosis or thromboembolism may play an important role in patients with collagen vascular disease. Especially in patients with lupus erythematosus and antiphospholipid antibodies, it is crucial to differentiate between associated and thromboembolic pulmonary hypertension. 


\section{Symptoms and diagnostic approach}

The leading symptom of pulmonary hypertension is dyspnoea on exertion. Further symptoms include palpitations and the development of oedema and ascites. The failure to increase cardiac output during exercise may lead to recurrent syncopes. Clinical findings of pulmonary hypertension are subtle in the beginning. A parasternal heave and a loud pulmonic second sound may be the only hints. A left parasternal systolic murmur may indicate the presence of tricuspid regurgitation. Other clinical signs such as jugular vein extension, ascites and oedema are due to overt right heart failure [29, 30].

Unfortunately, there is no early symptom or sign of pulmonary hypertension. When patients develop symptoms as described earlier, they usually suffer from advanced pulmonary hypertension with manifest low cardiac output.

Echocardiography is the most important diagnostic tool in patients with suspected pulmonary hypertension. Other noninvasive tools such as electrocardiograms or radiographs are less sensitive and accurate. Echocardiography should be used as a screening tool in patients at high risk for the development of pulmonary hypertension; in systemic sclerosis, CREST syndrome and mixed connective tissue disease, echocardiography should be performed routinely once a year. Stress echocardiography may be more sensitive than the standard echocardiography at rest, to detect early pulmonary hypertension [31]. It is not clear, however, what the therapeutic recommendations would be for patients with pulmonary hypertension during exercise, but normal pulmonary pressures at rest. Therefore, at this time, stress echocardiography cannot be recommended as a general screening tool for the identification of pulmonary hypertension.

If echocardiography unravels pulmonary hypertension, further investigations should determine the cause. A computed tomography scan of the lungs should be ordered to exclude pulmonary embolism and interstitial lung disease. Careful exclusion of thrombosis of the lower and upper extremities is necessary. If recurrent thromboembolism cannot be ruled out, pulmonary angiography should be considered. Finally, right heart catheterization is indicated to obtain a complete haemodynamic profile. During cardiac catheterization, a vasodilator trial with a short-acting substance such as inhaled nitric oxide, intravenous adenosine or aerosolized iloprost should be performed to guide further treatment [32-35].

\section{Treatment}

The approach to treat pulmonary hypertension in patients with collagen vascular disease can be divided in general measures, specific treatment of pulmonary hypertension and specific treatment of the underlying disease. General measures include the administration of oxygen in patients with documented hypoxaemia and the treatment of oedema or ascites with diuretics.
The efficacy of digitalis in patients with pulmonary hypertension and right heart failure is unproven but many centres use digitalis in patients with advanced right heart failure (New York Heart Association Class III or IV) [36]. Anticoagulation has been found to be effective in patients with PPH [37, 38]. Although there are no comparable data for patients with associated pulmonary hypertension, anticoagulation is generally recommended for these patients unless there is an increased risk of bleeding. The target international normalized ratio for patients with PAH is unknown but most centres recommend levels between 1.5-3.0.

Specific management of pulmonary hypertension should be guided by the clinical picture and the results of acute vasodilator challenge during right heart catheterization. A trial of calcium channel blockers is warranted only in patients who exhibit a marked pulmonary vasoreactivity (as defined by a fall in pulmonary artery pressure and pulmonary vascular resistance by $>20 \%$ from base line during acute vasodilator challenge) $[32,33]$.

In the vast majority of patients with $\mathrm{PAH}$ and collagen vascular disease, prostacyclin/-analogues are a central part of treatment. Continuous intravenous prostacyclin (epoprostenol) has been shown in randomized studies to be effective for $\mathrm{PPH}$, and has been approved in the USA as well as in several European countries [39]. There are numerous reports on the efficacy of continuous intravenous prostacyclin in patients with collagen vascular disease [40-42] and only recently, a multicentre trial demonstrated efficacy of this treatment in patients with pulmonary hypertension associated with scleroderma or CREST syndrome [43]. Interestingly, some extrapulmonary manifestations of collagen vascular disease such as skin lesions in patients with scleroderma may also improve substantially during treatment with prostacyclin. The major drawback of treatment with continuous intravenous prostacyclin is the requirement of a permanent central venous line, which is prone to infectious complications. Therefore, attempts are being made to administer prostanoids via alternative routes.

Continuous subcutaneous administration of treprostinil (formerly denoted UT-15), a stable prostacyclin analogue has been shown in a large randomized controlled trial to improve exercise tolerance and haemodynamics in patients with PPH and associated PAH [44, 45]. Unfortunately, this therapy is associated with substantial infusion site complications such as pain and skin induration. These side-effects lower patient's acceptance of the treatment.

Oral beraprost has been licensed in Japan for PPH after a controlled study in 58 patients showed evidence for increased survival in patients with PPH treated with beraprost, compared to conventional treatment [46]. There is, however, no sufficient data on the long-term efficacy of beraprost and there is also no information about the use of beraprost in patients with collagen vascular disease. The results of a recently completed multicentre study on beraprost for primary and associated pulmonary hypertension have not yet been published. 
Inhaled iloprost, another stable prostacyclin analogue, has been introduced recently for noninvasive treatment of PAH [47]. There is considerable evidence for the efficacy of inhaled iloprost in $\mathrm{PPH}$ $[35,48,49]$ but experiences with inhaled iloprost in patients with collagen vascular disease are just casuistic. Thus, continuous intravenous prostacyclin remains the treatment of choice for pulmonary hypertension associated with collagen vascular disease but novel noninvasive alternatives deserve attention and may be used under close supervision of the patient.

Another group of substances that are currently being introduced in the treatment of pulmonary hypertension, are endothelin antagonists [50]. Plasma endothelin levels are increased in patients with systemic sclerosis but the association of increased endothelin levels and pulmonary hypertension is unclear [51]. Based on preliminary experiences in patients with $\mathrm{PPH}$, these substances offer a promising perspective especially in conjunction with prostanoids [50]. A recently completed randomized, placebo-controlled multicentre trial showed that the dual endothelin receptor antagonist bosentan improves exercise capacity, pulmonary arterial pressure and cardiac output in patients with $\mathrm{PPH}$ and $\mathrm{PAH}$ associated with CREST/scleroderma [52].

In patients, in whom pharmacological treatment fails to improve pulmonary hypertension, lung transplantation should be considered. Historically, the presence of collagen vascular disease has been judged as a contraindication against lung transplantation. Increasing clinical experience suggests that this dogmatic rule may no longer be justified since several centres have reported survival rates similar to other patient groups in patients with systemic diseases [53-55]. Lung transplantation may be an option for patients in whom the extrapulmonary manifestations are not severe and therefore not life threatening. Kidney function especially should be preserved. Based on these considerations, lung transplantation may be an option for selected patients with collagen vascular disease and pulmonary hypertension, especially those with scleroderma or the CREST syndrome.

It is unclear whether treatment of the underlying disease may affect the course of pulmonary hypertension. There are several case reports in the medical literature about regression of pulmonary hypertension during immunosuppressive therapy [56-59]. However, there are no clinical trials to support this approach. Therefore, it seems prudent to try corticosteroids or immunosuppressants in patients with active collagen vascular disease accompanied by pulmonary hypertension [60]. These patients should be followed carefully (which usually includes serial right heart catheterizations) and the decision whether to continue or discontinue treatment will have to be based on the clinical results. In patients with chronic systemic sclerosis or CREST syndrome who develop pulmonary hypertension, immunosuppressive drugs cannot be recommended unless there is evidence for active pulmonary fibrosis.

\section{Outlook}

With the introduction of prostanoids in the treatment of pulmonary hypertension, there is now for the first time a therapeutic option for this often fatal complication of collagen vascular disease. There is no evidence, however, that prostanoids do significantly affect the extrapulmonary manifestations of the underlying disease. Novel substances are being developed in an attempt to modify autoimmune disorders and fibrosis. There is hope that substances such as transforming-growth-factor-beta antibodies [61] may effectively slow or stop progression of collagen vascular disease and will also have a positive impact on the course of associated pulmonary hypertension.

\section{References}

1. Rich S. Executive summary from the world symposium on primary pulmonary hypertension 1998. http:// www.who.int/ncd/cvd/pph.html 1998, last updated 21 November 2001.

2. Devereux G, Evans MJ, Kerr KM, Legge JS. Pulmonary veno-occlusive disease complicating Felty's syndrome. Respir Med 1998; 92: 1089-1091.

3. Gugnani MK, Pierson C, Vanderheide R, Girgis RE. Pulmonary edema complicating prostacyclin therapy in pulmonary hypertension associated with scleroderma: a case of pulmonary capillary hemangiomatosis. Arthritis Rheum 2000; 43: 699-703.

4. Morassut PA, Walley VM, Smith CD. Pulmonary veno-occlusive disease and the CREST variant of scleroderma. Can J Cardiol 1992; 8: 1055-1058.

5. Asherson RA, Asherson TW, Higenbottam TW, Ding Xuan AT, Khamashta MA, Hughes RV. Pulmonary hypertension in a lupus clinic: Experience with twentyfour patients. J Rheumatol 1990; 17: 1292-1298.

6. Pan TL, Thumboo J, Boey ML. Primary and secondary pulmonary hypertension in systemic lupus erythematosus. Lupus 2000; 9: 338-342.

7. Shen JY, Chen SL, Wu YX, et al. Pulmonary hypertension in systemic lupus erythematosus. Rheumatol Int 1999; 18: 147-151.

8. Yamane $\mathrm{K}$, Ihn $\mathrm{H}$, Asano $\mathrm{Y}$, et al. Clinical and laboratory features of scleroderma patients with pulmonary hypertension. Rheumatology 2000; 39: $1269-1271$.

9. Murata I, Takenata K, Yoshinoya S, et al. Clinical evaluation of pulmonary hypertension in systemic sclerosis and related disorders. A Doppler echocardiographic study of 135 Japanese patients. Chest 1997; 111: $36-43$.

10. Hoffman RW, Greidinger EL. Mixed connective tissue disease. Curr Opin Rheumatol 2000; 12: 386-390.

11. Yousem SA. The pulmonary pathologic manifestations of the CREST syndrome. Hum Pathol 1990; 21: 467-474.

12. Salerni R, Rodnan GP, Leon DF, Shaver JA. Pulmonary hypertension in the CREST syndrome variant of progressive systemic sclerosis. Ann Intern Med 1977; 86: 394-399.

13. Tuder RM, Groves B, Badesch DB, Voelkel NF. Exuberant endothelial cell growth and elements of inflammation are present in plexiform lesions of 
pulmonary hypertension. Am J Pathol 1994; 144: 275285.

14. Wagenvoort C, Wagenvoort N. Primary pulmonary hypertension: a pathological study of the lung vessels in 156 clinically diagnosed cases. Circulation 1970; 42: 1163-1184.

15. Pietra GG, Edwards WD, Kay JM, et al. Histopathology of primary pulmonary hypertension. A qualitative and quantitative study of pulmonary blood vessels from 58 patients in the National Heart, Lung, and Blood Institute, Primary Pulmonary Hypertension Registry. Circulation 1989; 80: 1198-2106.

16. Cool CD, Kennedy D, Voelkel NF, Tuder RM. Pathogenesis and evolution of plexiform lesions in pulmonary hypertension associated with scleroderma and human immunodeficiency virus infection. Hum Pathol 1997; 28: 434-442.

17. Cool CD, Steward JS, Werahera P, et al. Threedimensional reconstruction of pulmonary arteries in plexiform pulmonary hypertension using cell-specific markers. Am J Pathol 1999; 155: 411-419.

18. Mitani Y, Ueda M, Komatsu R, et al. Vascular smooth muscle cell phenotypes in primary pulmonary hypertension. Eur Respir J 2001; 17: 316-320.

19. Deng Z, Morse JH, Slager S, et al. Familial primary pulmonary hypertension (Gene PPH-1) is caused by mutations in the bone morphogenetic protein receptor-II gene. Am J Hum Genet 2000; 67: 737-744.

20. Machado RD, Pauciulo MW, Thomson JR, et al. BMPR2 haploinsufficiency as the inherited molecular mechanism for primary pulmonary hypertension. $\mathrm{Am}$ J Hum Genet 2001; 68: 92-102.

21. Thomson JR, Machado RD, Pauciulo MW, et al. Sporadic primary pulmonary hypertension is associated with germline mutations of the gene encoding BMPR-II, a receptor member of the TGF- $\beta$ family. J Med Genet 2000; 37: 741-745.

22. Wilkins MR, Gibbs JSR, Shovlin CL. A gene for primary pulmonary hypertension. Lancet 2000; 356: 1207-1208.

23. Morrell NW, Yang X, Upton PD, et al. Altered growth response of pulmonary artery smooth muscle cells from patients with primary pulmonary hypertension to transforming growth factor- $\beta 1$ and bone morphogenetic proteins. Circulation 2001; 104: 790795.

24. Humbert M, Monti G, Fartoukh M, et al. Plateletderived growth factor expression in primary pulmonary hypertension: comparison of HIV seropositive and HIV seronegative patients. Eur Respir J 1998; 11: $554-559$.

25. Eddahibi $\mathrm{S}$, Humbert $\mathrm{M}$, Sediame $\mathrm{S}$, et al. Imbalance between platelet vascular endothelial growth factor and platelet-derived growth factor in pulmonary hypertension. Am J Respir Crit Care Med 2000; 162: 1493-1499.

26. Voelkel NF, Hoeper M, Maloney J, Tuder RM. Vascular endothelial growth factor in pulmonary hypertension. Ann N Y Acad Sci 1996; 796: 186-193.

27. Welsh CH, Hassell KL, Badesch DB, Kressin DC, Marlar RA. Coagulation and fibrinolytic profiles in patients with severe pulmonary hypertension. Chest 1996; 110: 710-717.

28. Hoeper MM, Sosada M, Fabel H. Plasma coagulation profiles in patients with severe primary pulmonary hypertension. Eur Respir J 1998; 12: 1446-1449.

29. Rich S, Dantzker DR, Ayres SM, et al. Primary pulmonary hypertension. A national prospective study. Ann Intern Med 1987; 107: 216-223.

30. Rubin LJ. Primary pulmonary hypertension. $N$ Engl J Med 1997; 336: 111-117.

31. Grünig E, Janssen B, Mereles D, et al. Abnormal pulmonary artery pressure response in asymptomatic carriers of primary pulmonary hypertension gene. Circulation 2000; 102: 1145 .

32. Raffy $\mathrm{O}$, Azarian $\mathrm{R}$, Brenot $\mathrm{F}$, et al. Clinical significance of the pulmonary vasodilator response during short-term infusion of prostacyclin in primary pulmonary hypertension. Circulation 1996; 93: 484 488.

33. Sitbon $\mathrm{O}$, Humbert $\mathrm{M}$, Jagot JL, et al. Inhaled nitric oxide as a screening agent for safely identifying responders to oral calcium-channel blockers in primary pulmonary hypertension. Eur Respir J 1998; 12: 265-270.

34. McLaughlin VV, Genthner DE, Panella MM, Rich S. Reduction in pulmonary vascular resistance with longterm epoprostenol (prostacyclin) therapy in primary pulmonary hypertension. N Engl J Med 1998; 338: 273-277.

35. Hoeper MM, Olschewski H, Ghofrani HA, et al. A comparison of the acute hemodynamic effects of inhaled nitric oxide and aerosolized iloprost in primary pulmonary hypertension. $J$ Am Coll Cardiol 2000; 35: 176-182.

36. Rich S, Seidlitz M, Dodin E, et al. The short-term effects of digoxin in patients with right ventricular dysfunction from pulmonary hypertension. Chest 1998; 114: 787-792.

37. Rich S, Kaufmann E, Levy PS. The effect of high doses of calcium-channel blockers on survival in primary pulmonary hypertension. $N$ Engl $J$ Med 1992; 327: 76-81.

38. Fuster V, Steele PM, Edwards WD, Gersh BJ, McGoon MD, Frye RL. Primary pulmonary hypertension: natural history and the importance of thrombosis. Circulation 1984; 70: 580-587.

39. Barst RJ, Rubin LJ, Long WA, et al. A comparison of continuous intravenous epoprostenol (prostacyclin) with conventional therapy for primary pulmonary hypertension. The Primary Pulmonary Hypertension Study Group. N Engl J Med 1996; 334: 296-302.

40. McLaughlin VV, Genthner DE, Panella MM, Hess DM, Rich S. Compassionate use of continuous prostacyclin in the management of secondary pulmonary hypertension: a case series. Ann Intern Med 1999; 130: 740-743.

41. Menon N, McAlpine L, Peacock AJ, Madhok R. The acute effects of prostacyclin on pulmonary hemodynamics in patients with pulmonary hypertension secondary to systemic sclerosis. Arthritis Rheumat 1998; 41: 466-469.

42. Robbins IM, Gaine SP, Schilz R, Tapson VF, Rubin LJ, Loyd JE. Epoprostenol for treatment of pulmonary hypertension in patients with systemic lupus erythematodes. Chest 2000; 117: 14-18.

43. Badesch DB, Tapson VF, McGoon MD, et al. Continuous intravenous epoprostenol for pulmonary hypertension due to the scleroderma spectrum of disease. Ann Intern Med 2000; 132: 425-434.

44. Barst RJ, Simonneau G, Rich S, Blackburn SD, Naeije R, Rubin LJ. Efficacy and safety of chronic subcutaneous infusion UT-15 in pulmonary arterial hypertension. Circulation 2000; 102: 100-101. 
45. Bailey CL, Channick RN, Rubin LJ. A new era in the treatment of primary pulmonary hypertension. Heart 2001; 85: 252.

46. Nagaya $\mathrm{N}$, Uematsu M, Okano $\mathrm{Y}$, et al. Effect of orally active prostacyclin analogue on survival of outpatients with primary pulmonary hypertension. J Am Coll Cardiol 1999; 34: 1188-1192.

47. Olschewski H, Walmrath D, Schermuly R, Ghofrani A, Grimminger F, Seeger W. Aerosolized prostacyclin and iloprost in severe pulmonary hypertension. Ann Intern Med 1996; 124: 820-824.

48. Olschewski H, Ghofrani HA, Schmehl T, et al. Inhaled iloprost to treat severe pulmonary hypertension. An uncontrolled trial. Ann Intern Med 2000; 132: 435-443.

49. Hoeper MM, Schwarze M, Ehlerding S, et al. Longterm treatment of primary pulmonary hypertension with aerosolized iloprost, a prostacyclin analogue. $N$ Engl J Med 2000; 342: 1866-1870.

50. Williamson DJ, Wallman LL, Jones R, et al. Hemodynamic effects of Bosentan, an endothelin receptor antagonist, in patinets with pulmonary hypertension. Circulation 2000; 102: 411-418.

51. Morelli S, Ferri C, Di Francesco L, et al. Plasma endothelin-1 levels in patients with systemic sclerosis: influence of pulmonary or systemic arterial hypertension. Ann Rheum Dis 1995; 55: 794-795.

52. Channick RN, Badesch DB, Tapson VF, et al. Effects of the dual endothelin receptor antagonist bosentan in patients with pulmonary hypertension: a placebocontrolled study. J Heart Lung Transplant 2001; 20: 262-263.

53. Pigula FA, Griffith BP, Zenati MA, Dauber JH, Yousem SA, Keenan RJ. Lung transplantation for respiratory failure resulting from systemic disease. Ann Thorac Surg 1997; 64: 1630-1634.

54. Rosas V, Conte JV, Yang SC, et al. Lung transplantation and systemic sclerosis. Ann Transplant 2000; 5: 38-43.

55. Levy RD, Guerraty AJ, Yacoub MH, Loertscher R. Prolonged survival after heart-lung transplantation in systemic lupus erythematosus. Chest 1993; 104: 1903 1905.

56. Mariette X, Brenot F, Brouet JC. Recovery from pulmonary hypertension with steroid therapy in a patients with Sjogren's syndrome and polymyositis. J Rheumatol 1994; 21: 772-773.

57. Morelli S, Giordano M, De Marzio P, Priori R, Sgreccia A, Valesini G. Pulmonary arterial hypertension responsive to immunosuppressive therapy in systemic lupus erythematosus. Lupus 1993; 2: $367-$ 369.

58. Lahaye IE, Rogiers PE, Nagler JM, Chappel R. Vanishing pulmonary hypertension in mixed connective tissue disease. Clin Rheumatol 1999; 18: 4547.

59. Bellotto F, Chiavacci P, Laveder F, Angelini A, Thiene G, Marcolongo R. Effective immunosuppressive therapy in a patients with primary pulmonary hypertension. Thorax 1999; 54: 372-374.

60. Davas EM, Peppas C, Maragou M, Alvanou E, Hondros D, Dantis PC. Intravenous cyclophosphamide pulse therapy for the treatment of lung disease associated with scleroderma. Clin Rheumatol 1999; 18: 455-461.

61. Cotton SA, Herrick AL, Jayson MIV, Freemont AJ. TGF- $\beta$ - a role in systemic sclerosis. J Pathol 1998; 184: 4-6. 